\title{
EFFECT OF LAYERING ON DYNAMIC MECHANICAL PROPERTY OF GLASS FIBRE REINFORCED EPOXY COMPOSITE
}

\author{
Kunwar Rohit ${ }^{a}$ M. K. Gupta ${ }^{a}{ }^{*}$ Sunil Singh Rana ${ }^{\text {a }}$, Md. Saddam Hussain ${ }^{\text {a }}$ \\ ${ }^{a}$ Department of Mechanical Engineering, Motilal Nehru National Institute of Technology \\ Allahabad, Allahabad -211004, India \\ *mnnit.manoj@gmail.com
}

\begin{abstract}
-
In present work, glass fibre reinforced epoxy composite is prepared using hand lay-up technique by incorporating different no. of layers $(3,6,9$ and 12) of glass fibre into epoxy matrix. The dynamic mechanical properties of prepared composite is determined in terms of storage modulus $\left(E^{\prime}\right)$, loss modulus ( $\left.E^{\prime \prime}\right)$ and damping ( $\operatorname{Tan} \delta$ ). The test is carried out using three point bending mode at $5 \mathrm{~Hz}$ frequency. The results show that storage modulus is found to decease with increase in temperature in all cases. Loss modulus is found to increase up to glass transition temperature $\left(T_{g}\right)$ then decrease on increase in temperature. Damping is found minimum for glass composites and maximum for epoxy.

Keywords: Glass fibre; Epoxy resin; Dynamic mechanical properties; Hand lay-up technique.
\end{abstract}

\section{INTRODUCTION}

Recently, fibre reinforced polymer composites (FRPC) are considered as the most promising structural materials in sustainable engineering technology. In FRPC, reinforcement may be synthetic fibres (glass, carbon etc.) or natural fibres (banana, glass, sisal, hemp, bamboo etc.) while matrix materials may be either thermosets or thermoplasts. Many researchers have reported that natural fibre reinforced polymer composites are capable to replace synthetic fibre for medium strength applications for environmental concern [1-6]. The dynamic mechanical analysis is being very popular technique to characterize the thermal properties of FRPC. Thermal property as glass transition temperature of these composite can be obtained from peak of either storage modulus or loss modulus.

DMA measures the viscoelastic behaviour of polymer based materials. The viscoelastic property of a polymer materials is studied by dynamic mechanical analysis where a sinusoidal force (stress $\sigma$ ) is applied on a material and the resulting displacement (strain) is measured. The resulting strain and the stress will be in same phase when material is perfectly elastic but there will be a 90 degree phase lag of strain with respect to stress for purely viscous fluid. Viscoelastic polymers have the characteristics in between where some phase lag will occur during DMA tests.

Viscoelastic properties such as stiffness, glass transition temperature and damping can be obtained from storage modulus, loss modulus and tan delta curve. In present communication, viscoelastic properties in terms of storage modulus, loss modulus and damping of glass fibre reinforced epoxy composites are studied at $5 \mathrm{~Hz}$ frequency in temperature range $20{ }^{\circ} \mathrm{C}-200^{\circ} \mathrm{C}$.

\section{MATERIALS AND METHODS}

\subsection{Materials}

Glass fibres is used as reinforcement and epoxy resin as a matrix in this work. Glass fibre and epoxy matrix are purchased from local resource. Epoxy resin (Araldite Klear $4+$ ) and corresponding curing agent (Hardener Klear 4+) are mixed in ratio of 10:8 to make the matrix as recommended by suppliers.

\subsection{Fabrication of composites}

The composites are fabricated by reinforcing woven glass fibres into epoxy matrix by hand- lay- up technique. A stainless steel mould having dimensions of $300 \times 200 \times 3 \mathrm{~mm}^{3}$ is used to maintain the required thickness of composites. A releasing agent is used to assist easy removal of the composite from the mould after curing. The cast of each composite is cured under a load of $50 \mathrm{~kg}$ for 24 hours before it is removed from the mould. The specimens for DMA are cut as per ASTM standard using a diamond cutter. The composites manufactured with varying wt. \% of fibres are designated as G3 (3 layers of glass fibre), G6 (6 layers of glass fibre), G9 (9 layers of glass fibre) and G12 (12 layers of glass fibre).

\subsection{Dynamic Mechanical Analysis}

The dynamic mechanical properties of glass fibre reinforced epoxy composite are studied using the dynamic mechanical analyzer (Seiko instruments DMA 6100). The dynamic mechanical properties are determined in 3 point bending test as a function of temperature. The composites are cut into samples having dimensions of $50 \mathrm{~mm} \times 13 \mathrm{~mm} \times 3 \mathrm{~mm}$ as per ASTM D 5023. Experiments are carried out in the temperature range of $25-200{ }^{\circ} \mathrm{C}$ at $5 \mathrm{~Hz}$ frequency. The dynamic mechanical properties such as storage modulus, loss modulus and damping of prepared glass composites are studied in present work.

\subsection{Storage modulus $\left(E^{\prime}\right)$}

\section{Results and Discussions}

Fig. 1 shows the variation of storage modulus of glass composites as a function of temperature at $5 \mathrm{~Hz}$ frequency. Storage moduli of glass composites increase with increase in layers of woven glass fibre in epoxy matrix. In the glassy region, increase in storage modulus follows the order: G12 > 


\section{Asia Pacific Journals}

G9 > G6 > G3 . In all cases, the storage moduli are found to decrease with increase in temperature. This is due to loss in stiffness of fibres at high temperature [7]. In transition region, it is seen that all glass composites have gradual fall in value of $E^{\prime}$ with increase in temperature. In rubbery region, it is observed that the glass composite G12 has highest value of $E^{\prime}$ whereas G6 has its lowest value. The lowest value of $E^{\prime}$ shows increase in molecular mobility [8]. In rubbery region the storage moduli of glass composites are not close to each other. This is because at high temperature the fibres contribute much to impart stiffness to materials [9].

\subsection{Loss modulus $\left(E^{\prime \prime}\right)$}

Glass transition temperature is defined as point where materials changes from glassy to rubbery state. It can be obtained from either peak of loss modulus or tan delta curve. Loss modulus presents the viscous response of the materials which depends upon motion of molecules in composites. The variation of loss modulus of glass composites as a function of temperature at $5 \mathrm{~Hz}$ frequency is shown in Fig. 2. It is seen that the value of $E^{\prime \prime}$ increased up to glass transition temperature $\left(T_{g}\right)$ and then decreased with increase in temperature. The glass composite G3 has lower value of loss modulus as compared to other glass composites due to increase in molecular mobility into epoxy matrix. The value of $\mathrm{Tg}$ for the glass composites which is obtained from loss modulus curve is given in Table 1.

\subsubsection{Damping ( $\operatorname{Tan} \delta$ )}

Tan delta or damping is the ratio of loss modulus and storage modulus which is related to impact resistance of materials. The variation of damping of epoxy and glass composite as a function of temperature is shown in the Fig. 3. The glass composite G12 has highest peak of $\operatorname{Tan} \delta$ curve which shows better damping as compared to other glass composites. The peak of $\operatorname{Tan} \delta$ curve for glass composites follows the order: G12 > G9 > G6 > G3. Shifting of $T g$ towards higher temperature is found for glass composite G12. This is due to decreased mobility of chain by addition of glass fibres into epoxy matrix. The glass composite G12 has higher value of $\operatorname{Tg}\left(77.53^{\circ} \mathrm{C}\right)$ which shows the better thermal stability than other glass composites. The value of $T g$ obtained from $\operatorname{Tan} \delta$ curve for glass composites is given in Table 1.

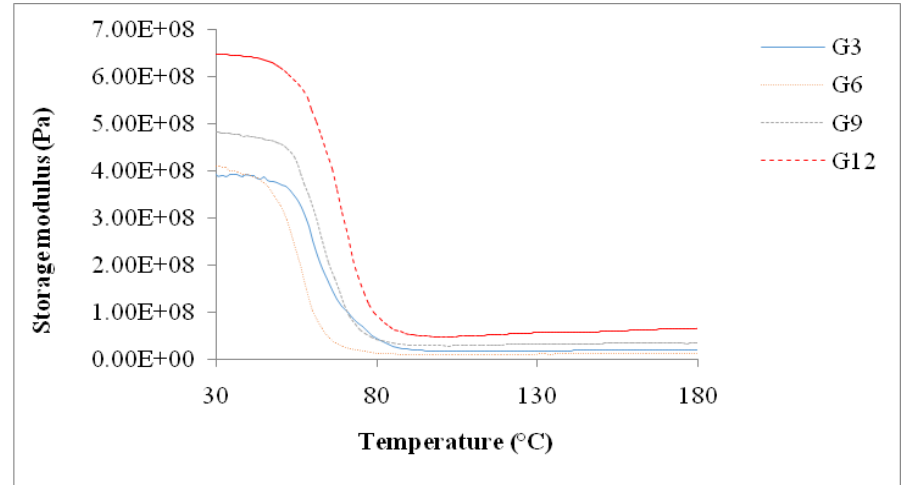

Fig. 1 Variation of storage modulus of glass composites with temperature

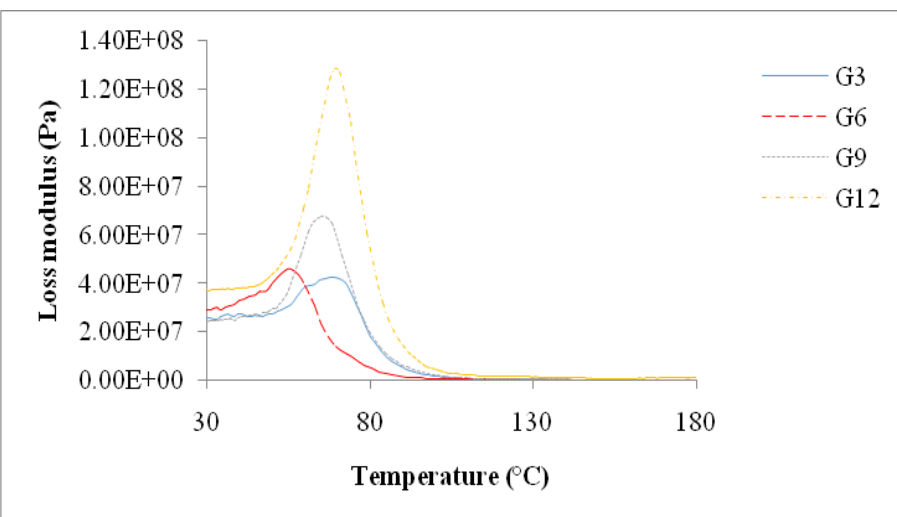

Fig. 2 Variation of loss modulus of glass composites with temperature

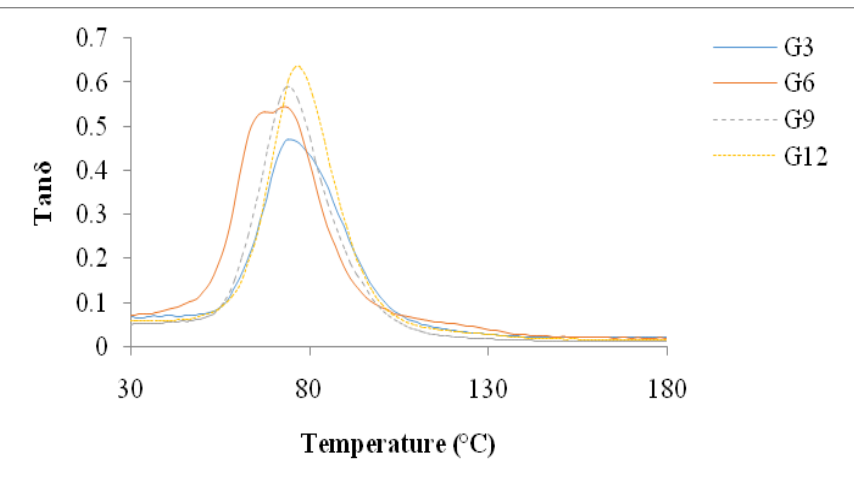

Fig. 3 Variation of Tan $\delta$ of glass composites with temperature

Table 1. Peak height and glass transition temperature $\left({ }^{\circ} \mathrm{C}\right)$ from loss modulus and tan delta curve

\begin{tabular}{|l|l|l|l|l|}
\hline Composites & $\begin{array}{l}\text { Peak height } \\
\text { of loss } \\
\text { modulus curve }\end{array}$ & $\begin{array}{l}\text { Peak height } \\
\text { of Tan delta } \\
\text { curve }\end{array}$ & $\begin{array}{c}T_{g} \text { from } \\
\text { Loss modulus } \\
\text { curve }\end{array}$ & $\begin{array}{l}T_{g} \text { from } \\
\text { Tan delta } \\
\text { curve }\end{array}$ \\
\hline G3 & $4.26 \mathrm{E}+7$ & 0.47 & 69.36 & 74.08 \\
\hline G6 & $4.60 \mathrm{E}+7$ & 0.54 & 56.15 & 74.06 \\
\hline G9 & $6.77 \mathrm{E}+7$ & 0.59 & 65.18 & 73.25 \\
\hline G12 & $1.29 \mathrm{E}+8$ & 0.63 & 69.29 & 77.53 \\
\hline
\end{tabular}




\section{Asia Pacific Journals}

\section{IV.CONCLUSIONS}

Storage modulus, loss modulus and damping are found to increase with increase in glass fibres content in epoxy matrix. The glass composite G12 has highest value of storage modulus, loss modulus and damping than other glass composites. Glass transition temperature has shifted to higher temperature for glass composite having maximum content of glass fibres.

\section{Acknowledgement}

The authors would like to thanks the Head of Mechanical Engineering Department of MNNIT Allahabad for their support in allowing us to perform the tests. The study is partially supported by Cumulative Professional Development Allowance Fund for teachers from MNNIT Allahabad.

\section{References}

[1]. M.K. Gupta, R.K. Srivastava, Polym. Plast. Technol. Eng. DOI:10.1080/03602559.2015.1098694.

[2]. M.K. Gupta, R.K. Srivastava, Mater. Today: Proceed. 2 (2015) 29092917.

[3]. H. Bisaria, M.K. Gupta, P. Sandilya, R.K. Srivastava, Mater. Today: Proceed. 2 (2015) 1193-1199.

[4]. H. Mourya, M.K. Gupta, R.K. Srivastava, H. Singh, Mater. Today: Proceed. 2 (2015) 1347-1355

[5]. M.K. Gupta, R.K. Srivastava, Int. J. Fib. Text. Res. 5 (2015) 30-38.

[6]. S. Husic, I. Javni, Z.S. Petrovic, Compos. Sci. Technol. 2005; 65: 19-25.

[7]. D. Shanmugam, M. Thiruchitrambalam, Mater. Des. 50 (2013) 533542.

[8]. L.A. Pothan, Oommen, Compos. Sci. Technol. 63 (2003) 283-293.

[9]. K.C.M. Nair, S. Thomas, G. Groeninckx, Compos. Sci. Technol. 61 (2001) 2519-2529 